\title{
Testing the Meta-Population Structure of the Endemic Lava Heron (ButoridesSundevalli) on the Archipelago Island System
}

\author{
Solomon Ayele Tadesse* \\ Department of Natural Resources Management, College of Agriculture and Natural Resource Sciences, DebreBerhan University, Ethiopia \\ "Corresponding author: Solomon Ayele Tadesse, DebreBerhan University,Department of Natural Resources Management, Col- \\ lege of Agriculture and Natural Resource Sciences, DebreBerhan, Ethiopia. Tel: +251-1116815440; Fax: +251-1116812065; Email: \\ solomon.ayele1972@gmail.com \\ Citation: Tadess SA (2018) Testing the Meta-Population Structure of the Endemic Lava Heron (ButoridesSundevalli) on the \\ Archipelago Island System, Curr Trends Forest Res: CTFR-109. DOI: 10.29011/CTFR-109.100009
}

Received Date: 29 January, 2018; Accepted Date: 7 March, 2018; Published Date: 13 March, 2018

\begin{abstract}
The probabilities of species colonization and extinction rates of meta-populations on island system could be affected by fraction of islands occupied and size of each island. Meta-population models are relevant to understand the dynamics of endangered species which often persist in highly fragmented landscapes. The objectives of the study were to: (1) determine the meta-population dynamics of the endemic lava heron (Butoridessundevalli) on the archipelago island system through estimating the probabilities of colonization and extinction rates; (2) investigate the structure of meta-populations and their trends on the island system by using meta-population models. The results revealed that islands which are large in size showed a source-effect due to their positive internal rate of population growth, lower probabilities of extinction rates, and higher average abundance of population size. However, islands with small size had lower average abundance of population size and relativity lower (negative) internal rate of population growth so that they acted to play a sink-effect. In contrast to the prediction made by metapopulation model, the results of the comparison across the twelve islands showed that both the probabilities of colonization and extinction rates of the small sized islands were relatively higher than those islands with large size. However, across time frame comparison showed that the extinction probabilities increased with the increase in fraction of occupied islands though colonization probabilities showed a slight decline when the fraction of occupied islands increased. This suggested that the metapopulation structure of the endemic lava heron on the archipelago island system was found to be the combination of source-sink and core-satellite structure. Fraction of islands occupied, and the area of islands had a significant effect to predict the internal rates of population growth and the average abundance of population size for the endemic lava heron on the archipelago island system, respectively.
\end{abstract}

Keywords: Archipelago; Colonization; Core-Satellite; Extinction; Island System; Source-Sink

\section{Introduction}

Ecological studies on the distribution, abundance, species richness, and population dynamics of organisms are currently becoming hot issues in ecology and evolutionary biology as they are bases specifically for the conservation of endangered and threatened species at local and regional scales [1,2]. Metapopulation dynamics is a recent ecological concept dealing with the probabilities of species colonization and extinction rates on different landscapes including the island systems $[3,4]$. A meta-population refers to a population inhabiting a collection of discrete patches $[5,6]$. The probabilities of colonization and extinction rates of meta-population on the archipelago island system could be affected by the fraction of islands occupied, the size of each island, and distance between or among islands and/ or the mainland. This is because dispersal rate and colonization of populations of a species on a specific island is affected by its isolation (i.e. distance) from the mainland as a source-sink effect [7-9]. The concept of a biota in a contemporary equilibrium between colonization and extinction was also challenged by new finds of fossils $[3,5]$. It has not kept pace with relevant theory and our growing appreciation for the complexity of nature, especially with empirical findings that species diversity on many islands. This is because most islands are not in stable equilibrium as 


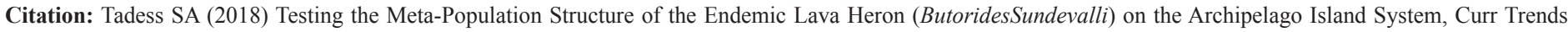
Forest Res: CTFR-109. DOI: 10.29011/CTFR-109. 100009

they are influenced by differences in speciation, colonization, and extinction among taxa; and also influenced by differences among islands in characteristics other than area and isolation (i.e. distance) [3]. Moreover, variation in the size and quality of patches [9] and variation due to different spatial arrangement of patches would have different effects on population dynamics [7-11].

Meta-population models are important tools to understand the distribution and abundance of organisms on large spatial scales $[3,4]$. This is because meta-population models describe an open system, in which extinction and colonization depends on the movement of individuals among a set of patchy sites [7-11]. Those models are especially relevant to understand the dynamics of endangered species which often persist in highly fragmented landscapes [12]. The dynamics of species living in fragmented landscapes has produced much information on the patterns of habitat patch occupancy in a wide range of organisms $[8,13]$. A lot of attempts were made to develop various models to test the meta-population dynamics largely relying on Monte Carlo simulations [14]. For example, Anderson [15] considered a stochastic continuous time meta-population model which explicitly models the size of each local population in a collection of variable sized patches. Hanski [13] looked at presence-absence data for meta-populations and used this to estimate probabilities of patch extinction and colonization. Of course, all over the world, species have faced loss and fragmentation of their natural habitats by anthropogenic factors $[7,12,16,17]$. The extinction of a species involves elements of chance. Hence, it is important to include stochastic influences when modeling a meta-population occupying a small number of patches $[3,7,8]$.

Most empirical ecologists that use meta-population concepts prefer to use the simpler Levin's model as it requires the least assumptions and requires that only colonization and extinction rates to be known $[4,18]$. Moreover, attempts made to find metapopulations in nature have been hampered by the difficulty in measuring the needed parameters and the amount of time required documenting reproduction, dispersal, extinction, and colonization [19]. Here I considered the twelve archipelago islands whose size ranges from 25 to 431 hectares. The objectives of the study were to: (1) determine the meta-population dynamics of the endemic lava heron (Butoridessundevalli) on the archipelago island system through estimating the probabilities of colonization and extinction rates; (2) investigate the structure of meta-populations and their trends on the island system by using meta-population models.

\section{Methods}

\section{Study Species}

The lava heron (Butoridessundevalli), also known as the Galápagos heron, is a species of heron endemic to the Galápagos Islands of Ecuador. The back feathers typically have a silvery sheen and it has a short crest on its head. When breeding, the lava heron has a black beak and bright orange legs, but these fade to grey after the breeding season. The lava herons are highly territorial birds and are found in intertidal zones and mangrove swamps on most of the islands of Galápagos Province. The lava heron stalks small crabs and fish slowly before quickly spearing and eating them. They have also been known to eat the flies that gather near cacti. Lava herons are typically seen hunched over and they have a sharp alarm call. Unlike most herons, these birds nest in solitary pairs in either the lower branches of mangrove trees or under lava rocks. Lava herons can breed year-round, though typically from September to March, and can mate up to three times a year [20].

\section{Statistical Tests}

With the assumption of equi-distances among the twelve islands for equal probabilities of colonization and extinction rates, the thirty years data were analyzed using mathematical models developed by meta-population ecologists $[3,4,19]$. Accordingly, probabilities of colonization and extinction rates of the endemic lava heron (Butoridessundevalli) on each island were computed to evaluate the dynamics of meta-population on the archipelago island system and later to interpret the ecological processes attributed for such dynamic nature on the island system. Thus, an occurrence matrix was constructed in which each row was used as a year whereas each column was treated as an island. In this matrix, an entry of one represents the presence of a population in the island during that particular year and a zero indicates the species was absent in that specified year in the island.

Following Gotelli and Taylor [19], I calculated f, the fraction of islands occupied, as: $\mathrm{f}=$ number of islands occupied in year $(\mathrm{t}) /$ number of islands that were censused in year (t). For each island, I also calculated the least square regression slope of the probability of extinction versus the fraction of islands occupied. Moreover, I tested whether the probability of local extinction decreases significantly as more islands were occupied.

Next, I calculated the probability of colonization (pi) for each island as followed. $\mathrm{pi}=$ number of unoccupied islands in year $(\mathrm{t})$ that were occupied in year $(t+1)$ / the number of islands that were censused in year $(\mathrm{t})$. For each island, I also calculated the least square regression slope of the probability of colonization versus the fraction of islands unoccupied. Hence, the t-test was used to evaluate the statistical significance of the regression slope.

I also calculated pe, the probability of extinction between each pair of consecutive years as followed. $\mathrm{pe}=$ number of islands occupied in year $(\mathrm{t})$ that were unoccupied in year $(\mathrm{t}+1) /$ number of islands occupied in year ( $\mathrm{t})$. Hence, for the census data of the 30 years, there were 29 annual probabilities of extinction that could be calculated. Moreover, I calculated the internal rate of population growth for the endemic lava heron on each island. 


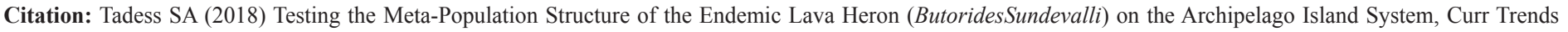
Forest Res: CTFR-109. DOI: 10.29011/CTFR-109. 100009

This activity is important to evaluate the effect of internal rate of population growth on meta-population structure as source-sink effect. Accordingly, the internal rate of population growth on each island was calculated as followed:

$\mathrm{r}=\mathrm{b}-\mathrm{d}$

Where,

$\mathrm{r}=$ internal rate of population growth for each island

$\mathrm{b}=$ birth rate on each island

$\mathrm{d}=$ death rate on each island

Finally, I calculated the average abundance of lava heron population on each island over the thirty years time span. Average abundance $=$ the summation of the populations on each island over the thirtyyear time / 30 .

\section{Testing the Premises of Meta-Population Models}

The two basic premises of meta-population models were tested with the results obtained from the analyzed data. One of the premises is that meta-population has reached an equilibrium state in which local extinctions are balanced by local colonization $[4,19]$. Thus, if equilibrium has not been reached, probabilities of extinction and colonization rates will change with time. To test this premise, I first computed the probabilities of colonization (pi) and extinction (pe) over the 30 years period. Next, I measured the slope of the relationship between probabilities of colonization (pi) and extinction (pe) rates across the twelve islands. Hence, the null hypothesis is that the slope does not differ significantly from zero.

The second premise was taken from [8] meta-population models whose premise was that islands are homogenous so that the probabilities of local colonization (pi) and extinction (pe) rates are the same across all islands. In this study, the size of each island is different (i.e. the size ranges from 25 to 431 hectares) so that it is more likely to affect the probabilities of colonization (pi) and extinction (pe) rates. Thus, I calculated the probabilities of colonization (pi) and extinction (pe) rates across the twelve islands, and evaluated whether these probabilities were significantly correlated with the size of the twelve islands.

For all analyses, I defined the alpha value to be 0.05 and performed the analyses with SPSS version 16.

\section{Results}

The results revealed that the fraction of islands occupied (f) across the 12 islands on the archipelago island system had a mean value of $0.44, \mathrm{SE}=0.10$; a maximum value of 0.58 , a minimum value of 0.25 , and the range value of 0.33 . The results further showed that the probability of colonization (pi) across the 12 islands had a mean value of $0.23, \mathrm{SE}=0.02$; a maximum value of 0.50 , but the minimum value was 0.00 whereas the range was 0.50 . With regard to the probability of extinction (pe) across the 12 islands, the mean, the maximum, and the minimum values were $0.28,0.67$, and 0.00 , respectively; with $\mathrm{SE}=0.03$ and a range of 0.67 (Table 1).

\begin{tabular}{|c|c|c|c|c|c|c|c|c|c|c|c|c|c|c|c|}
\hline \multirow{2}{*}{ Year } & \multicolumn{12}{|c|}{ Islands } & \multirow{2}{*}{ f } & \multirow{2}{*}{ pi } & \multirow{2}{*}{ pe } \\
\hline & 1 & 2 & 3 & 4 & 5 & 6 & 7 & 8 & 9 & \# & \# & 12 & & & \\
\hline 1 & 0 & 1 & 1 & 1 & 0 & 1 & 0 & 1 & 0 & 0 & 0 & 0 & 0 & 0 & 0 \\
\hline 2 & 0 & 0 & 1 & 1 & 0 & 1 & 0 & 0 & 0 & 0 & 0 & 0 & 0 & 0 & 0 \\
\hline 3 & 0 & 0 & 1 & 1 & 0 & 1 & 1 & 0 & 0 & 0 & 0 & 0 & 0 & 0 & 0 \\
\hline 4 & 1 & 0 & 1 & 1 & 0 & 1 & 1 & 0 & 0 & 0 & 0 & 0 & 0 & 0 & 0 \\
\hline 5 & 0 & 0 & 1 & 1 & 0 & 1 & 1 & 0 & 0 & 0 & 0 & 0 & 0 & 0 & 0 \\
\hline 6 & 0 & 1 & 1 & 1 & 0 & 1 & 1 & 0 & 0 & 0 & 1 & 0 & 1 & 0 & 0 \\
\hline 7 & 1 & 0 & 1 & 1 & 0 & 1 & 1 & 0 & 1 & 0 & 0 & 1 & 1 & 0 & 0 \\
\hline 8 & 0 & 0 & 1 & 1 & 0 & 0 & 1 & 1 & 1 & 0 & 0 & 1 & 1 & 0 & 0 \\
\hline 9 & 0 & 1 & 1 & 1 & 1 & 0 & 1 & 1 & 0 & 0 & 0 & 0 & 1 & 1 & 1 \\
\hline 10 & 1 & 0 & 1 & 1 & 0 & 1 & 1 & 0 & 0 & 0 & 1 & 0 & 1 & 0 & 0 \\
\hline 11 & 1 & 0 & 1 & 0 & 0 & 1 & 1 & 0 & 0 & 0 & 0 & 0 & 0 & 0 & 0 \\
\hline 12 & 0 & 0 & 1 & 0 & 0 & 1 & 1 & 0 & 1 & 1 & 0 & 1 & 1 & 1 & 1 \\
\hline 13 & 0 & 1 & 0 & 1 & 0 & 1 & 0 & 0 & 0 & 0 & 1 & 0 & 0 & 0 & 0 \\
\hline
\end{tabular}




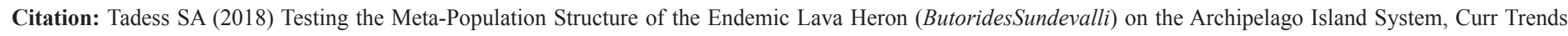
Forest Res: CTFR-109. DOI: 10.29011/CTFR-109. 100009

\begin{tabular}{|c|c|c|c|c|c|c|c|c|c|c|c|c|c|c|c|}
\hline 14 & 0 & 1 & 1 & 1 & 0 & 1 & 1 & 0 & 0 & 0 & 1 & 0 & 0 & 0 & 0 \\
\hline 15 & 1 & 0 & 1 & 1 & 0 & 1 & 1 & 1 & 0 & 0 & 1 & 0 & 1 & 0 & 0 \\
\hline 16 & 0 & 0 & 1 & 1 & 0 & 1 & 1 & 0 & 0 & 0 & 1 & 0 & 0 & 0 & 0 \\
\hline 17 & 0 & 0 & 1 & 1 & 0 & 0 & 1 & 0 & 1 & 0 & 0 & 1 & 0 & 0 & 0 \\
\hline 18 & 1 & 0 & 1 & 1 & 0 & 0 & 1 & 0 & 1 & 0 & 0 & 1 & 1 & 0 & 1 \\
\hline 19 & 0 & 1 & 1 & 1 & 0 & 1 & 1 & 0 & 0 & 0 & 0 & 0 & 0 & 0 & 0 \\
\hline 20 & 0 & 0 & 1 & 1 & 0 & 1 & 1 & 1 & 0 & 0 & 0 & 0 & 0 & 0 & 0 \\
\hline 21 & 0 & 1 & 1 & 1 & 1 & 1 & 0 & 1 & 0 & 0 & 0 & 0 & 1 & 1 & 0 \\
\hline 22 & 0 & 0 & 1 & 1 & 0 & 1 & 1 & 1 & 0 & 1 & 1 & 0 & 1 & 0 & 1 \\
\hline 23 & 0 & 0 & 1 & 1 & 0 & 1 & 1 & 0 & 0 & 0 & 0 & 0 & 0 & 0 & 0 \\
\hline 24 & 1 & 0 & 1 & 1 & 0 & 1 & 1 & 0 & 0 & 0 & 0 & 0 & 0 & 0 & 0 \\
\hline 25 & 1 & 1 & 1 & 1 & 1 & 0 & 1 & 0 & 0 & 0 & 0 & 0 & 1 & 1 & 1 \\
\hline 26 & 0 & 0 & 1 & 1 & 0 & 1 & 1 & 0 & 1 & 0 & 1 & 1 & 1 & 0 & 0 \\
\hline 27 & 0 & 0 & 1 & 1 & 0 & 1 & 1 & 0 & 0 & 0 & 0 & 0 & 0 & 0 & 0 \\
\hline 28 & 0 & 1 & 1 & 1 & 0 & 1 & 1 & 0 & 1 & 0 & 0 & 1 & 1 & 0 & 1 \\
\hline 29 & 0 & 0 & 1 & 1 & 0 & 1 & 0 & 1 & 0 & 0 & 0 & 0 & 0 & 0 & 0 \\
\hline 30 & 1 & 0 & 1 & 1 & 0 & 1 & 1 & 0 & 0 & 0 & 0 & 0 & 0 & -- & - \\
\hline $\mathrm{f}$ & 0.3 & 0 & 1 & 1 & 0 & 1 & 1 & 0 & 0 & 0 & 0 & 0 & & & \\
\hline pi & 0.2 & 0 & 0 & 0 & 0 & 0 & 0 & 0 & 0 & 0 & 0 & 0 & & & \\
\hline pe & 0.2 & 0 & 0 & 0 & 0 & 0 & 0 & 0 & 0 & 0 & 0 & 0 & & & \\
\hline $\mathrm{r}$ & -0 & -0 & 0 & 0 & -0 & 0 & 0 & -0 & $\#$ & -0 & -0 & -0 & & & \\
\hline Aver. N & 1.6 & 1 & 20 & 16 & 0 & 11 & \# & 1 & 1 & 0 & 1 & 1 & & & \\
\hline
\end{tabular}

Table 1: Data matrix and meta-population calculations for the endemic lava heron (Butoridessundevalli). Each entry showed the presence (1) or absence $(0)$ of a population in the island at a particular year. $\mathrm{f}=$ fraction of islands occupied; $\mathrm{pi}=$ probability of colonization; $\mathrm{pe}=$ probability of extinction, $\mathrm{r}=$ the internal rate of population growth; $\mathrm{N}$ = average abundance of the population on each island. For meta-population analyses, the values of $\mathrm{f}$, pi, and pe were calculated across the 12 islands and over the 30 years' time span. However, $r$ and $N$ were only computed over the 30 years' time span. The overall frequency ( $\mathrm{f}$ ) of the endemic lava heron population was calculated across the twelve islands over the 30 years period.

The results revealed that the fraction of islands occupied (f) over the 30 years period on the archipelago island system had a mean value of $0.44, \mathrm{SE}=0.02$; a maximum value of 0.97 whereas the minimum value was 0.07 , but the range was 0.90 . The results further showed that the probability of colonization (pi) over the 30 years period on the island system had a mean value of 0.13 , SE $=0.03$; a maximum value of 0.24 , but the minimum value was 0.03 with a range of 0.21 . With regard to the probability of extinction (pe) over the 30 years period on the island system, the mean, the maximum, and the minimum values were $0.13,0.28$, and 0.03 , respectively but $\mathrm{SE}=0.04$; and the range was 0.25 . The internal rate of population growth ( $\mathrm{r}$ ) over the 30 years period on the island system had a mean value of $0.0002, \mathrm{SE}=0.01$; maximum value of 0.03 , and a minimum value of -0.02 , but the range was 0.05 . Furthermore, the average abundance of lava heron population on each island over the 30 years' time span had mean $=5.35$, $\mathrm{SE}=2.04$; whereas the maximum and minimum values were 19.6 and 0.1 , respectively but the range was 19.5 . The overall frequency of the lava heron population across the twelve islands over the 30 years period on the archipelago island system was 0.44 (Table 1). 
The results revealed that, in contrast to the prediction of the simple meta-population models, the probability of colonization showed a negative regression slope (-0.0293) (Figure 1) though the fraction of islands occupied (f) increased over the 30 years span. This suggested that the null hypothesis was accepted because the slope of this relationship was very close to zero as the $\mathrm{P}$ value was ( $\mathrm{P}$ $=0.25$ ). Moreover, the results showed that the probability of colonization (pi) did not vary with the fraction of islands occupied (f) over the 30 years period, implying a constant propagule rain.

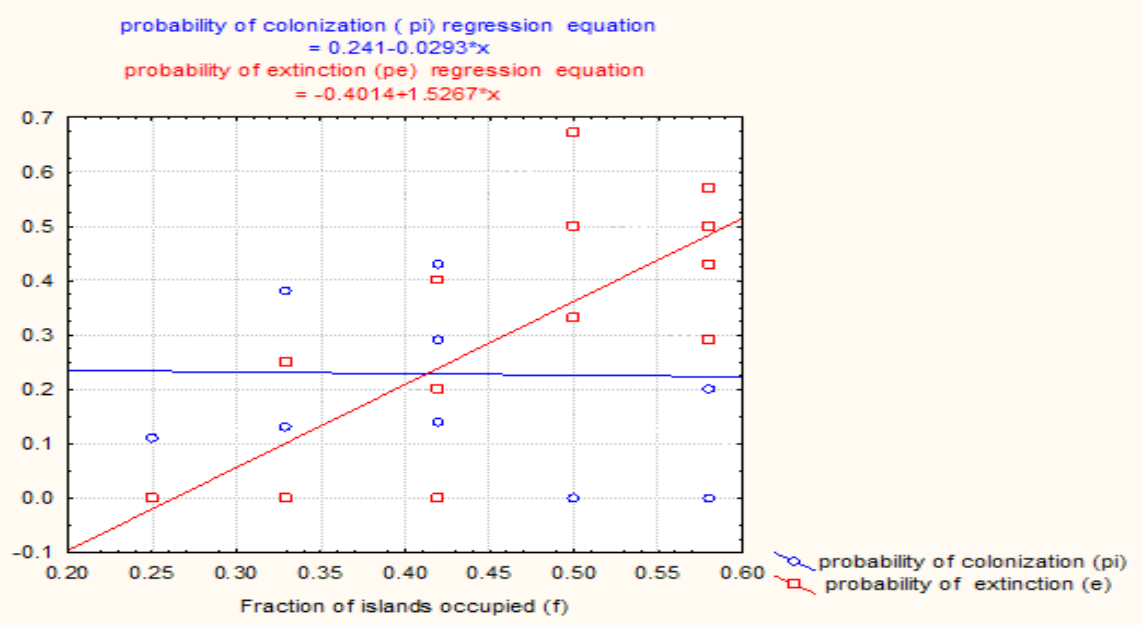

Figure 1: The probabilities of colonization (pi) and extinction (pe) of the population of the endemic lava heron (Butoridessundevalli)as a function of the fraction of islands occupied (f) over the 30 years' time span.

The prediction of simple meta-population models suggested that the probability of extinction is positively influenced by the rescue effect. This means that the probability of extinction should decrease as a fraction of islands occupied increased. However, the results of the present study showed that the probability of extinction increased as the fraction of islands occupied (f) increased over the 30 years span. This is in contrast to the prediction made by the meta-population model of the rescue effect because the probability of extinction showed a positive regression slope (1.5267) (Figure 1) which was significantly different from zero as the $\mathrm{P}$ value was $(\mathrm{P}<0.001)$.

In line with the prediction made by the meta-population model, the average abundance of population on each island (N) increased with the increase in the fraction of islands occupied (f) across the twelve islands because the average abundance of the population showed a positive regression slope (0.497) (Figure $2 \mathrm{a}$ ) which was significantly different from zero as the $\mathrm{P}$ value was $(\mathrm{P}<0.05)$. Moreover, the internal rate of population growth on the islands increased with the increase in the area of islands because the internal rate of population growth showed a positive regression slope (0.453) (Figure $2 \mathrm{~b}$ ) which was significantly different from zero as the $\mathrm{P}$ value was $(\mathrm{P}<0.05)$. 
Citation: Tadess SA (2018) Testing the Meta-Population Structure of the Endemic Lava Heron (ButoridesSundevalli) on the Archipelago Island System, Curr Trends Forest Res: CTFR-109. DOI: 10.29011/CTFR-109. 100009



(a) Fraction of occupied islands (f)

Internal rate of population growth $=-0.026+0.453 \mathrm{x}$

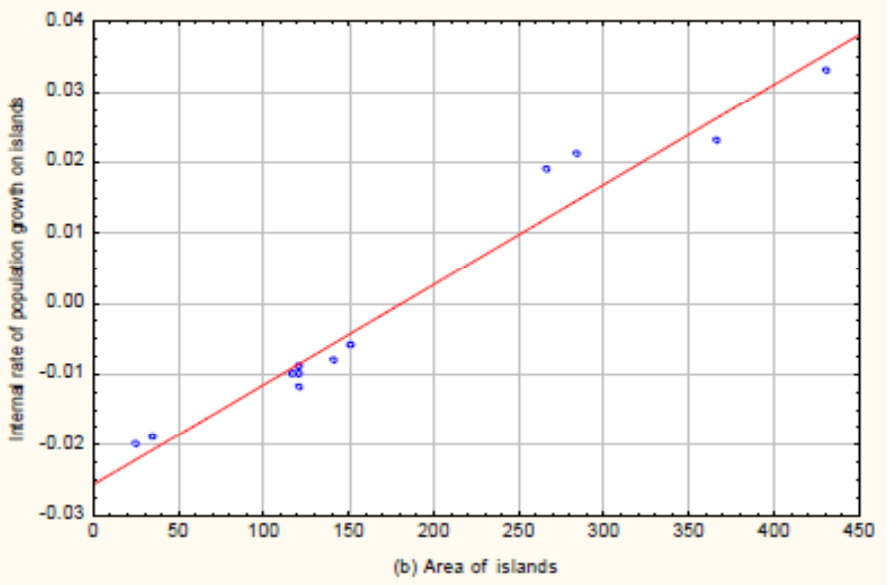

Figure 2: The average abundance of the population of the endemic lava heron (Butoridessundevalli)as a function of the fraction of islands occupied (f) (a), and the internal rate of population growth as a function of area of islands (b) across the twelve islands. The area of each island was expressed in hectares.

In the case of across islands comparison, both colonization and extinction probabilities showed a decline with the increase in the fraction of occupied islands because the probability of colonization showed a negative regression slope (-0.1059) (Figure $3 a)$ but not different from zero as the $P$ value was $(P>0.05)$. And the probability of extinction showed a similar negative regression slope (-0.0926) (Figure 3a) which was not different from zero as the $\mathrm{P}$ value was $(\mathrm{P}>0.05)$. The same trend was also observed on the probabilities of colonization (pi) and extinction (pe) as the area of islands increased because the probability of colonization had a negative regression slope (-0.1063) (Figure 3b) which was not different from zero as the $\mathrm{P}$ value was $(\mathrm{P}>0.05)$. And the probability of extinction had also a negative regression slope
$(-0.1076)$ (Figure 3b) which was not different from zero as the $\mathrm{P}$ value was $(\mathrm{P}>0.05)$.

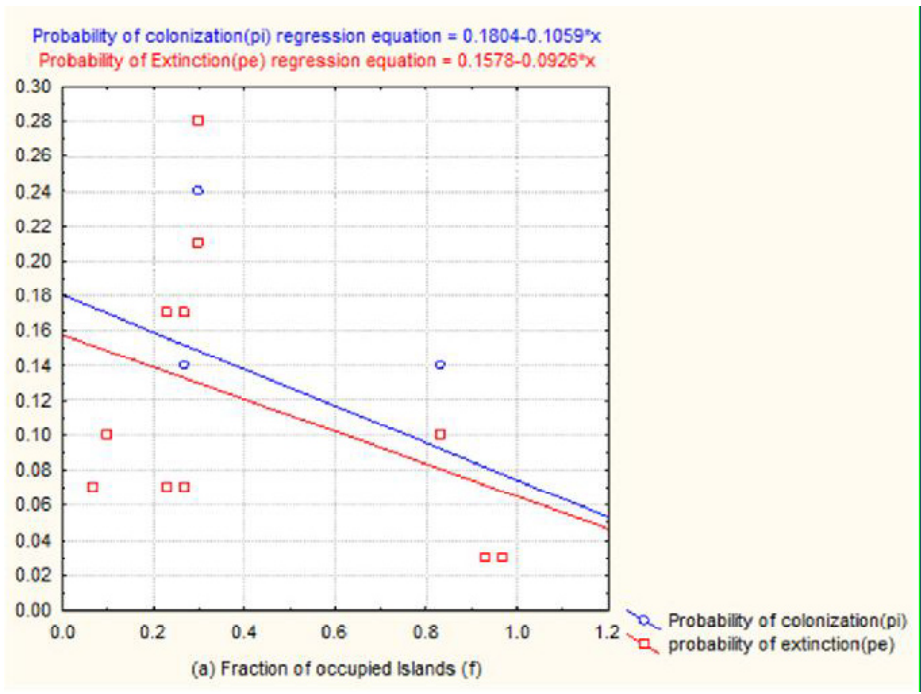

Probabily of colonization ( $(0)$ regression equation $=0.1812-0.1063 \times \mathrm{X}$ Probabiliry of Exthction(pe) regression equation $=10.1636-0.1076 \times \mathrm{X}$

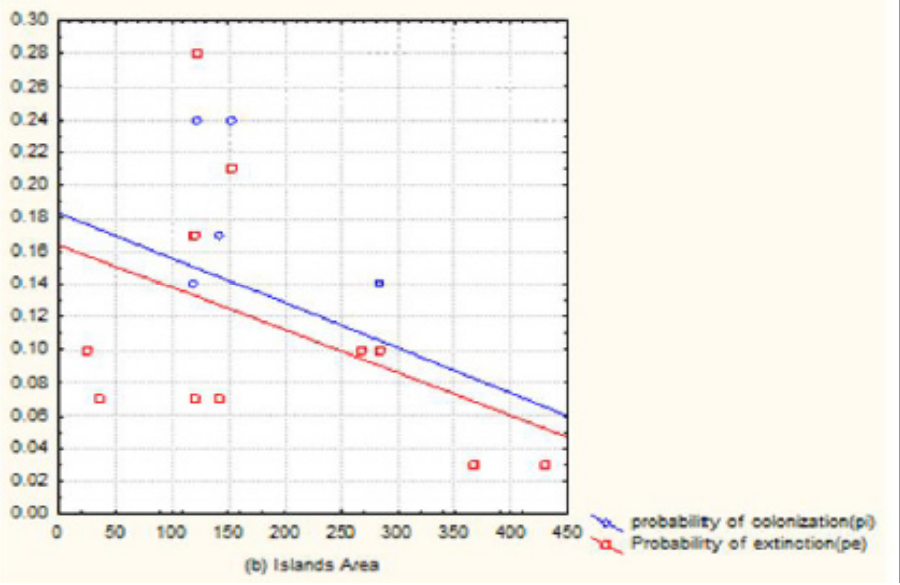

Figure 3: The probabilities of colonization (pi) and extinction (pe) of the population of the endemic lava heron (Butoridessundevalli)as a function of the fraction of islands occupied (f) (a), and probabilities of colonization (pi) and extinction (pe) as a function of area of islands (b) across the twelve islands.

\section{Discussion}

Estimating the probabilities of colonization and extinction for meta-populations is a basis to look into the dynamics, abundance, and distribution of populations on the archipelago island system where species have faced a problem of habitat fragmentation followed by local extinction $[3,4,12,13,17]$. It is also important to provide basic field information for the conservation of species with meta-populations that are liable to extinctions in different temporal scales but rescued through colonization $[4,19]$. With regard to the 
time frame comparison over the thirty years census period, in contrast to the predictions made by the meta-population models, extinction probabilities increased with the fraction of occupied islands (f) though colonization probabilities showed a slight decline when the fraction of occupied islands increased (Figure 1). Gottile and Taylor [19] also got a similar result on eight species of fish while testing the meta-population model on the stream-fish populations where the result showed opposite to the prediction of the meta-population rescue effect. Perhaps this similar result for the endemic lava heron suggested that meta-population models are more appropriate for certain other taxa, such as butterflies [21,22] and shrews [23].

The first premise of meta-population model is to reach an equilibrium state when local extinctions are balanced by local colonization [19]. In the present study, it was estimated that the equilibrium state reached at 0.24 (Figure 1). However, the second premise of meta-population model which was suggested by [8] was violated in the present study because the probabilities of extinction and colonization were not homogenous (Figure 1).

The results of the present study showed that average abundance of population increased when the fraction of islands occupied (f) increased (Figure 2a). This is in line with the prediction made by the meta-population models. This suggested that the average abundance of population $(\mathrm{N})$ increased when islands are more occupied by individuals resulting from colonization from the nearby area (e.g., dispersal) or positive internal rate of population growth. In line with the prediction made by metapopulation models, the result further revealed that international rate of population growth (r) increased with the increase in the area of islands (Figure 2b). For example, according to [9], one of the possible reasons could be positive internal rate of population growth. The other reason is that the ecological niches on large islands are not filled so that there will be high reproduction as there is no resource limitation due to competition. Generally, the results suggested that those islands with low average abundance of populations $(\mathrm{N})$ and/or negative internal rates of population growth (r) are satellite populations whereas islands with high average abundance of populations $(\mathrm{N})$ and/or positive internal rate of population growth $(\mathrm{r})$ are core populations $[4,9,24]$ on the archipelago island system.

The average abundance-incidence and distribution of lava heron across the twelve islands (Figure 2a, b) showed that there is a core-satellite meta-population. This is because islands with large size have shown positive internal rate of population growth so that they are core populations [24] compared with islands with small size and negative internal rate of population growth (Figure $2 b)$ which are satellite population in the meta-population dynamic model $[3,9]$ of the archipelago island system. Generally, the results of the present study suggested that the meta-population structure of the endemic lava heronon the archipelago island system should be the combination of source-sink and core-satellite structure. Moreover, in natural systems, Hanski [4] and Pulliam [9] and noted that meta-populations are distributed across their habitats depending on temporal and spatial variations whose effects cannot be explained by a single model. For example, various metapopulation models also predicted that the occurrence of coresatellite structure in natural system so that it is crucial to conserve meta-populations with different abundance-incidence parameters and playing as source-sink effect $[13,14,24,25]$.

Across islands comparison, both the probabilities of colonization and extinction showed a decline with the increase in the fraction of occupied islands (Fig. 3a) and the same situation was also observed to the probabilities of colonization and extinction as the areas of islands increased (Figure 3b). This showed that islands with big area play a source-effect whereas islands with small area play a sink-effect [9].

In the present study, the probabilities of extinction decreased with the increase in islands area was in line with the prediction made by the meta-population models $[3,4,19]$. The size of each island is different so that it is likely to affect the probability of colonization (pi) and extinction (pe). However, in contrast to the prediction of meta-population models $[3,4]$, both the probabilities of extinction and colonization decreased with the increase in area of islands. One of the possible reasons is that colonization is more than just dispersal; when a propagule reaches a new patch, it faces higher extinction probabilities than does an established population [26,27]. Gotelli and Taylor [19] also noted that in the absence of meta-population dynamics, propagules could arrive from a large constant, e. g., 'mainland' source, in which case the probability of colonization would be independent of site occupancy (due to the island-mainland model).

Various theoreticaland empirical studies [3,5,6,9,11,12,27,28] suggested that distances between or among adjacent islands and/ or mainland (i.e. isolation), organismic behavior, speciation, locomotion ability of individuals of a species, and migration could substantially affect the probabilities of colonization (pi), extinction (pe), average abundance of population on each island $(\mathrm{N})$, and internal rate of population growth (r) on the archipelago island system. Moreover, competition [29], predation [7], natural and man-made barriers (e.g., topography, wind, climate change, dams, etc.), biological invasion [30], genetic variability and body size [31], the relative position of each island in relation to other islands and/or mainland $[19,32,33]$, quality and spatial arrangements of patches (i.e. habitat heterogeneity and complexity) $[7,10]$, and human-induced disturbances (e.g., logging, hunting, burning, habitat destruction and fragmentation, settlement, livestock freerange grazing, etc.) [17] could influence the structure, distribution, and abundance of meta-population. Thus, I recommend that future 
Citation: Tadess SA (2018) Testing the Meta-Population Structure of the Endemic Lava Heron (ButoridesSundevalli) on the Archipelago Island System, Curr Trends Forest Res: CTFR-109. DOI: 10.29011/CTFR-109. 100009

study should incorporate all the aforementioned factors into the meta-population models to test and precisely predict pi, pe, N, and $r$ values on the archipelago island system.

\section{Acknowledgements}

First of all, I would like to forward my sincere gratitude to YaronZiv for his continuous guidance and relevant reading materials for this study. During this research, the State of Israel provided financial assistance.

\section{Conflict of Interest}

The author declares that there is no conflict of research interest.

\section{References}

1. Morris DW, Kotler BP, Brown JS, Sundararaj V, Ale SB (2009) Behavioral indicators for conserving mammal diversity. Annals of New York Academy of Science 1162: 334-356.

2. Primack RB (2002) Essentials of conservation biology. Inc. Publishers, Massachusetts, USA. Third edition. Pg. No: 698.

3. Hanski I (1991) Single-species meta-population dynamics: concepts, models and observations. Biological Journal of the Linnean Society 42: 17-38.

4. Hanskil (1999) Meta-population ecology. Oxford University Press, Oxford UK.

5. Hanski I, Gilpin M (1991) Meta-population dynamics: brief history and conceptual domain. Biological Journal of the Linnean Society 42: 3-16.

6. Harrison S (1989) Long-distance dispersal and colonization in the Bay checkerspot butterfly, EuphydryasEdithaBayensis. Ecology 70: 12361243.

7. Harrison S (1991) Local extinction in a meta-population context: an empirical evaluation. Biological Journal of the Linnean Society 42: 73-88.

8. Levins R (1969) Some demographic and genetic consequences of environmental heterogeneity for biological control, Bull. Entomol Soc Am 15: $237-240$.

9. Pulliam HR (1988) Sources, sinks, and population regulation. Am Nat 132: 652-661.

10. Doak DF, Mills SL (1994) A useful role for theory in conservation. Ecology 75:615-626.

11. Holt RD (1992) A neglected facet of island biogeography: the role of internal spatial dynamics in area effects. TheorPopulBiol 41: 354-371.

12. Wilcox BA, Murphy DD (1985) Conservation strategy: the effects of fragmentation on extinction. The American Naturalist 125: 879-887.

13. Hanski I (1994) A Practical model of meta-population dynamics. AnimEcol 63: 151-162.

14. Hanski I, Thomas CD (1994) Meta-population dynamics and conservation: a spatially explicit model applied to butterflies. BiolConserv 68: 167-180.

15. Anderson WJ (1991) Continuous-time Markov chains, Springer-Verlag, New York.
16. Hanski I (1994) Patch-occupancy dynamics in fragmented landscapes. Trends EcolEvol 9: 131-135.

17. Jagera HI, Chandlerb JA, Leplab KB, Winklec WV (2001) A theoretical study of river fragmentation by dams and its effects on white sturgeon populations. Environmental Biology of Fishes 60: 347-361.

18. Crone EE, Doak DF, Pokki J (2001) Ecological influences on the dynamics of a field vole meta-population. Ecology 82:831-843.

19. Gotelli JN, Taylor MC (1999) Testing meta-population models with stream-fish assemblages. Evolutionary Ecology Research 1: 835845

20. Heinzel H, Hall B (2000) Galapagos diary. $1^{\text {st }}$ Edition. Los Angeles; University of California Press, USA.

21. Hanski I, Kuussaar M, Nieminen M (1994) Meta-population structure and migration in the butterfly Melitaeacinxia. Ecology 75: 747-762.

22. Hanski I, PakkalaT, Kuussaari M, Nieminen M (1995) Meta-population persistence of an endangered butterfly in a fragmented landscape. Oikos 72 : 21-28

23. Peltonen A, Hanski I (1991) Patterns of island occupancy explained by colonization and extinction rates of shrews. Ecology 72: 1698-1708.

24. Schlosser IJ, Angermeier PL (1995) Spatial variation in demographic processes of lotic fishes: conceptual models, empirical evidence, and implications for conservation. Pg No: 392-401. In: J.L. Nielsen (ed.). Evolution and the Aquatic Ecosystem: Defining Unique Units in Population Conservation, American Fisheries Society, Bethesda.

25. Shaffer ML (1985) The meta-population and species conservation: the special case of the northern spotted owl. U.S. Department of Agriculture, Forest Service, General Technical Report PNW 185: 86-99.

26. Diamond JM (1974) Colonization of exploded volcanic islands by birds: the supertramp strategy. Science 184: 803-806.

27. Ebenhard T (1990) Reproductive traits and body size as adaptations to a colonization strategy in field voles (Microtus agrestis). Ecology71: 1833-1848.

28. Schaffter RG (1997) White sturgeon spawning migrations and location of spawning habitat in the Sacramento River, California. California Fish and Game 83: 1-20.

29. Bengtsson J (1991) Interspecific competition in meta-populations. Biological Journal of the Linnean Society 42: 219-237.

30. Mollison D (1986) Modeling biological invasions: chance, explanation, and prediction. Philosophical Transactions of the Royal Society of London 314: 675-693.

31. Ebenhard T (1991) Colonization in meta-populations: a review of theory and observations. Biological Journal of the Linnean Society 42: 105-121.

32. Osborne LL, Wiley MJ (1992) Influence of tributary spatial position on the structure of warm water fish communities. Can. J. Fish. Aquat. Sci 49: $671-681$

33. Taylor CM (1997) Fish species richness and incidence patterns in isolated and connected stream pools: effects of pool volume and spatial position. Oecologia 110: 560-566. 